\title{
Assessment of User Comfort Aspects of Industrialized Building Systems using PROMETHEE and Delphi
}

\author{
S. Shahbazi ${ }^{1}$, S. Sepasgozar ${ }^{2}$, and B.Shahbazi ${ }^{3}$ \\ ${ }^{1}$ PhD candidate, Department of Civil Engineering, University of Shahid Chamran, Ahwaz, Iran \\ ${ }^{2 \& 3}$ PhD candidate, School of Civil and Environmental Engineering, University of New South \\ Wales Australia, Sydney, Australia \\ ${ }^{2}$ Corresponding author's e-mail: samad.sepasgozar@gmail.com
}

\begin{abstract}
Modern construction methods and systems offer many advantages to project stakeholders. However, the process of decision making of selecting an appropriate system is complicated to clients of large and complex projects. The paper presents the result of the study in selecting a structural system out of five intensively used alternatives based on user comfort performance criteria. The alternatives were evaluated using a Delphi-type technique, because the result will be based on a consensus, and the discussion made during the interviews will provide profounder understanding of alternatives' priorities. A total of six participants from both academic and the construction industry were invited to carefully examine each alternative from both designer and construction performance point of views. They were asked to illustrate the advantages and disadvantages of each structural system considering all related factors such as material specifications, system requirements and limitations, and construction performance. The discussion is structured by using a framework consists of four main criteria: exploitation quality and hygiene, thermal and acoustic insulation, psychological issues, and architectural flexibility summarized by a consensus point. The participants also were asked to weight the criteria based on pairwise comparison technique. The alternative priorities and the weighted list of criteria then used as input of PROMETHEE to rank construction methods based on four 'user comfort' performance criteria. The result of the study reveals that Light Steel Frame (LSF) was the superior construction method in terms of user comfort performance criteria. The main reasons are that LSF has a higher performance in thermal and acoustic insulation and can be very flexible to various architectural plans. This paper contributes to the body of knowledge by utilising a procedure of decision making method to select to an appropriate industrialized building system by examining key factors of user comfort attributes.
\end{abstract}

\section{KEYWORDS}

Industrialized Building System (IBS), User Comfort, PROMETHEE, Multi Criteria Decision Making (MCDM), Light Steel Frame (LSF),

\section{INTRODUCTION}

Several factors are involved in selection of building construction method and numerous economic, technical, and social criteria are incorporated such as cost and time of project completion, enhancement of manpower productivity, the reduction of materials, the destructive 
effects on environment, and architectural flexibility of construction method. Blismas, Pasquire et al. (2006) concluded that industry compares various construction methods are simply based on material, labor and transportation costs, without explicit attention to the long-term cost and life cycle cost, health and safety, and energy consumption. Pan, Gibb et al. (2007) reported that the traditional drivers of time, cost, quality and productivity are still strong influencers for the housebuilders in deciding on construction methods . Despite this, first of all, house is built for benefit of dwellers. If we take a retrospective glance, we will notice that primary objective of building houses is for dwellers' convenience and satisfactory as they are user of product. Therefore, some of user comfort criteria such as quality and integrity of walls surface, thermal and acoustic insulation, feasibility of constructing curved walls and wide openings should take into account whilst analysing problem of IBS selection.

Despite the impacts and influence of user comfort perspectives, fewer studies utilized appropriate methods to precisely evaluate such systems from the perspectives. This paper answers the question which structural system is more satisfactory to be adopted by final users. Therefore, five selected structural systems will be assessed and compared through four user comfort criteria using a consensus based method called Delphi. In order to rank these systems the PROMETHEE method will be utilized. Exploitation of Delphi method in prioritization of alternatives and presenting expert reasons for supporting their opinions is one of the main values of this paper.

The originality of this paper lies in using Delphi technique, which is based on the consensus between domain experts in structural systems. This method will give deep understanding and more reliable results comparing structured questionnaires. Substantial reliance of results on deep interviews with building experts has commingled industrial part to this academic research. This paper is a step forward to give an understating of the priority of each structural system from factors dealing with dwellers' satisfactory. In addition, taking psychological issues in construction into account is another value of current paper which could be interesting and bring a new perspective in mind and solving the problem.

The results of this paper will assist clients and designers to choose a proper construction method based on user comfort criteria especially in mass-housing projects, its importance intensifies due to large amount of typical housing construction. The results also will be beneficial to high-level decision makers of governmental organizations in assessing the associated user comfort criteria of housing projects in which different structural systems may be used and make a balance between acting exclusively economic and being notice to social and user satisfaction parts of the projects.

The paper is organized as follows: Section 2 provides the fundamental concepts, advantages and disadvantages of under-investigation building systems. In the next section, alternatives valuation is accomplished using expert opinion and Delphi method. Afterward, weighting of criteria and alternatives ranking are presented in Section 4 and followed by conclusion in Section 5 .

\section{PROBLEM DEFINITION}

In this paper, five construction methods is assessing and comparing by four user comfort criteria. After necessary investigation, five prominent and competitive construction systems for building main structure of a house which have largely implemented all over the world are selected. They consist of steel structural system, LSF, ICF, Tunnel form system, and Kayson method which are briefly introduced on the following. Light Steel Frame (LSF) system is made of cold-formed steel members in order to provide structural stability, plates and plaster boards as the inner 
lining, insulation and acoustic layers, external wall components as facade, and complementary building elements (Paton-Cole, Gad et al. 2012). ICF system consists of walls and ceiling components in which interlocking Expanded Polystyrene (EPS) prefabricated panels is used to act as concrete form at the time of construction and concrete casting. These panels play roll of sound and thermal insulation at the time of exploitation (Karamlou and Kabir 2012). The tunnelform system is an industrialized construction technique in which building operations of reinforcement, formwork, and in situ concrete casting of structural walls and ceiling slabs are performed simultaneously using steel forms composed of vertical and horizontal panels set at right angles (Kalkan and Yüksel 2008). In industrial building system of integrated in-situ reinforced concrete (known as Kayson method), after integrated metal formwork of all exterior and interior walls in the same time, concrete casting action is done. Same procedure is performed for ceiling implementation. This building system leads to a structure with load bearing shear wall and slab, without beams and columns.

Four user comfort criteria are defined to indicate different aspects and perspectives of a construction method which brings about dwellers' satisfaction. To better understand the criteria, description of some of them is provided in the following.

- Exploitation quality and hygiene

Insects and rodents such as moth, cockroach and mouse could penetrate houses, and in case of appropriate environment and conditions for their penetration, nesting, and propagation, efface of them turned to a difficult task. Hollow walls of some building systems are considered very appropriate place for propagation of vermin.

- Thermal and acoustic insulation

Nowadays, importance of energy saving is clear to everyone. Therefore, buildings with higher energy saving features are considered more desirable. In addition, thermal and acoustic insulation play a crucial role in bringing user comfort.

- Psychological issues in building construction

Regarding the housing construction from a psychological perspective, it can be expressed that a home must be compatible to human mental needs. For example psychology of colors and color combinations used in doors and walls and windows should be under attention, and also shapes and spaces should inject energy, motivation, and sensation to dwellers. In addition, living room, bedrooms and the other components of the house should be designed such that convey a sense of security and tranquility. Applying psychological viewpoints in the design and construction of buildings can be very useful and helpful, and guide us to build "suitable houses for living and not being alive" (Misagh 2014).

- Architectural flexibility in design, implementation, and exploitation phases

Several aspects are to be considered when dealing with architectural flexibility criterion. Varied architecture plans which could be proposed and the extent which implementation considerations affect the architecture are getting under attention at architectural flexibility in design phase. For example, certain constraints exist in architectural plan of tunnel form buildings because of especial shape of forms which produce parallel walls. In implementation phase, instruction drawings might change due to client order, implementation problems occurrence, etc. Hence, it is a significant factor for construction methods to allow architecture changes easily and with 
minimum extra cost incurred. Ability to create various interior designs at exploitation time is deemed important from the perspective of dwellers. Concrete-based systems are generally rigid and do not allow users to make substantial changes and even reposition of non-bearing walls. In contrast, possibility of reposition and changes in structural walls in certain construction methods are also available.

\section{METHODS}

In this paper, PROMETHEE technique is utilized to rank construction methods based on user comfort criteria. The PROMETHEE is from family of outranking methods that were presented and developed by Brans, Vincke et al. (1986). PROMETHEE II provides a complete ranking of alternatives from the best to the worst. The basic principle of PROMETHEE II is based on a pairwise comparison of alternatives along each determined criterion or binary outranking relations. The implementation of the PROMETHEE II requires two piece of information as inputs: prioritizing alternatives (i.e. construction methods) and weights of criteria.

Priorities of five building systems based on the criteria were determined using Delphi method (Gupta and Clarke 1996). Six experts took part in Delphi technique including three faculty professors and three experienced building experts. All of the participants possessed sufficient capability, knowledge, professional qualifications, and relevant experience in construction method area. To gain deeper understanding and more reliable results of construction method selection process, respondents were interviewed through Delphi method. During interview session and after respondents made their selections, they were particularly asked to bring their reasons why they believed some building systems were less or more preferable than others from each criterion perspective.

A questionnaire was conducted to capture perceptions of the experts on the relative importance of the criteria. Participants were asked to rate criteria by nine-point scales ranging from 1 indicating "equal preference" to 9 "strongly dominance", and intermediate numbers representing partial dominance. To ensure a better understanding of the criteria, definition of them was clarified and guidance on completion was written in the questionnaire.

\section{RESULTS AND DISCUSSION Delphi Method}

Results of building systems' evaluation are shown in Table 1. Furthermore, experts' reasons and arguments about preference of different construction methods and their comparisons and assessments are demonstrated in the following.

Table 1. Evaluation of building systems

\begin{tabular}{|c|c|c|c|c|c|}
\hline $\begin{array}{l}\text { Building } \\
\text { technology } \\
\text { Criterion }\end{array}$ & $\begin{array}{l}\text { Insulated } \\
\text { Concrete } \\
\text { Form }\end{array}$ & $\begin{array}{l}\text { Light Steel } \\
\text { Frame }\end{array}$ & $\begin{array}{l}\text { Steel } \\
\text { structure } \\
\text { system }\end{array}$ & $\begin{array}{l}\text { Kayson } \\
\text { method }\end{array}$ & $\begin{array}{l}\text { Tunnel } \\
\text { form } \\
\text { system }\end{array}$ \\
\hline $\begin{array}{l}\text { Exploitation quality and } \\
\text { hygiene }\end{array}$ & 4 & 2 & 7 & 9 & 9 \\
\hline $\begin{array}{l}\text { Thermal and acoustic } \\
\text { insulation }\end{array}$ & 8 & 9 & 5 & 4 & 4 \\
\hline $\begin{array}{l}\text { Psychological issues in } \\
\text { building construction }\end{array}$ & 5 & 2 & 9 & 6 & 4 \\
\hline Architectural flexibility & 5 & 9 & 7 & 3 & 2 \\
\hline
\end{tabular}


- Exploitation quality and hygiene

Cleaning tunnel-form and Kayson systems is easier than LSF and ICF. If a corrosion in a part of foam occurs, an appropriate space would be created for insect penetration and propagation. Hammering a nail for tables make some holes in walls which beside empty spaces behind LSF walls consider ideal place to growing and reproduction of all kinds of insects and even mice. In concrete-based systems, this problem does not exist.

From the exploitation quality point of view it could be said that LSF walls could simply be scratched by a knife or dented by hitting which does not convey a good sense to dwellers. Generally, LSF components did not possess high exploitation strength. For example, putting barbecue on the balcony close to the wall can damage the walls of the LSF; plaster leaves get folded or the contents inside of walls such as glass wool and insulation materials lose their initial performance owing to low heating strength.

- Thermal and acoustic insulation

In case that proper insulation layers are used in peripheral walls and ceiling and thermal joints are covered well, LSF system has incredible performance in energy saving. Thermal conduction coefficient of polystyrene boards used in ICF system is $0.25 \sim 0.35 \mathrm{~W} / \mathrm{m} 2 . \mathrm{k}$ which is approximately $30 \%$ of common materials used in buildings' walls and ceiling. Because of using brick in steel building system, better sound insulation performance is yielded comparing concrete buildings. For example, percussion sound transmission does not exist in steel building systems while this issue gets intensified in concrete buildings due to the integration of concrete in walls and ceiling.

- Psychological issues in building construction

Arbitrary changes in order to promote psychological factors such as change in ceiling height, changes in structural and partition walls, and ability of combination with various supplementary operations systems are faced with many restrictions in concrete buildings. Fixed formwork system of Kayson and tunnel-form methods cause limitations when variety in stories such as openings and windows places is need. Moreover, possibility of implementation of any model, design, artificial stone, etc. is not provided on the concrete surface of walls and ceiling which limits interior design options to observe psychological points.

Thin and light walls of LSF system do not inspire sense of security to dwellers. Although soft and light structures have more resistance against earthquake, they also do not provide adequate psychological and mental comfort against the earthquake for users.

Regarding all psychologically important issues including transferring sense of security and calmness, strength and thickness of the walls, architectural spaces, arbitrary size and shape of windows, short and tall ceilings, structural stability, the amount of incoming sun light, providing sufficient social distances in different parts of structure, structural steel system obtains highest preference in comparison with other building systems.

- Architectural flexibility in design, implementation, and exploitation phases

Architectural Flexibility when utilizing large and fixed forms are certainly more confined than small forms. In tunnel form structures, main walls remain solid and non-changeable after concrete casting, but partition walls could be placed anywhere. In Kayson method, even changes in partition walls are not allowed due fixed and integrated forms. 
Steel frames is generally very compatible with architecture and different plans, while the reinforced concrete frame has comparatively huge size in beams and columns which in addition to reduction of useful house area, forms undesirable excrescence in walls and other architectural spaces. Particular architecture operations such as creation of arches and curves are not feasible in LSF. In addition to the flexibility of steel buildings in the design of the skeleton, design and selection of partition walls are accomplished with wide choices. ICF has limitations in construction of wide openings and curved walls.

\section{Criteria weighting}

Pairwise comparisons of user comfort criteria are shown Table 2.

Table 2. Pairwise comparison matrix of user comfort criteria

\begin{tabular}{lccccc}
\hline & $\begin{array}{l}\text { Exploitation } \\
\text { quality and } \\
\text { hygiene }\end{array}$ & $\begin{array}{l}\text { Thermal and } \\
\text { acoustic } \\
\text { insulation }\end{array}$ & $\begin{array}{l}\text { Psychological } \\
\text { issues in } \\
\text { construction }\end{array}$ & $\begin{array}{l}\text { Architectural } \\
\text { flexibility }\end{array}$ & $\begin{array}{l}\text { Weight } \\
\text { (percentage) }\end{array}$ \\
\hline $\begin{array}{l}\text { Exploitation quality and } \\
\text { hygiene }\end{array}$ & 1 & 0.25 & 1 & 0.2 & 1 \\
$\begin{array}{l}\text { Thermal and acoustic } \\
\text { insulation }\end{array}$ & 4 & 1 & 3 & 0.25 & 35.95 \\
$\begin{array}{l}\text { Psychological issues in } \\
\text { building construction } \\
\text { Architectural flexibility }\end{array}$ & 1 & 0.33 & 1 & 1 & 43.31 \\
\hline
\end{tabular}

\section{PROMETHEE results}

Visual PROMETHEE is the Software which has used to calculate net outranking flow for each alternative and present complete ranking of PROMETHEE method after required data entry. Positive, negative, and net flows for each construction method are given in Table 3 . These flows are indicator values which show how much an alternative is dominated by other alternatives or dominated them. PROMETHEE I used positive and negative flow values to find the partial ranking whereas net flow are used in PROMETHEE II to identify the complete ranking. Results introduce LSF as best and Tunnel form system as worst construction method based on user comfort criteria.

Table 3. Positive, negative, and net flows of alternatives

\begin{tabular}{lllll}
\hline Ranking & Building Systems & Phi & Phi+ & Phi- \\
\hline 1 & Light Steel Frame (LSF) & 0.5980 & 0.7990 & 0.2010 \\
2 & Steel structure system & 0.3229 & 0.6614 & 0.3386 \\
3 & Insulated Concrete Form (ICF) & 0.1308 & 0.5654 & 0.4346 \\
4 & Kayson method & -0.3644 & 0.2606 & 0.6250 \\
5 & Tunnel form system & -0.6873 & 0.0992 & 0.7864 \\
\hline
\end{tabular}

As can be seen, LSF, structural steel system, ICF, Kayson method, and tunnel form system were respectively ranked first to fifth according to PROMETHEE outputs. According to expert opinions, LSF possess significantly higher performance in thermal and acoustic insulation. This system also allows designers to come up with various architectural plans. LSF gained low marks from exploitation quality and psychosocial issues but its performance at two other more important criteria was enough good to make it selected as preferable system. Steel structure system was known to have the most compatibility to psychological requirements of the building. 
Possibility of construction of curved walls and wide openings make it to be a flexible system in architecture and plan designing of the building. These reasons made steel structure system to gain second rank. According to achieved results, ICF is known as a mediocre construction method which attains intermediate grades in most of performance criteria except its high thermal insulation produced because of polystyrene boards used in ICF walls and ceiling. Strict architectural limitation of tunnel form and Kayson methods due to their integrated framework system caused them to be placed $4^{\text {th }}$ and $5^{\text {th }}$.

\section{CONCLUSION}

The purpose of the paper was to examine a well-known consensus method to evaluate the structural systems based on 'user comfort' performance criteria. It also was aimed to provide a deep understanding of the specifications of the structural systems in terms of user comfort criteria including exploitation quality and hygiene, thermal and acoustic insulation, psychological issues in building construction, architectural flexibility. The investigated structural systems are Light Steel Frame (LSF), Insulated Concrete Form (ICF), Steel Building System, Tunnel Form System, and Industrial Building System of integrated in-situ reinforced concrete (known as Kayson method). Structural systems were prioritized through a Delphi-type survey of six industry and academic experts. In order to gain deeper understanding and more reliable results of construction method selection process, the participants were asked to explain their viewpoints and reasons about priorities of structural systems. Next, four user comfort criteria were weighted and structural systems were ranked based on the criteria by PROMETHEE technique. The result of the study reveals that LSF was selected as the preferable construction method through four user comfort criteria and steel structural system, ICF, Kayson method, and tunnel form system were respectively ranked second to fifth. The interviews provided several reasons to support the selected system (i.e. LSF), such as being completely flexible to many architecture operations such as creation of arches and curves, changing position of partition walls, and also great performance in thermal and sound insulation which has a pronounced influence in user comfort and satisfaction.

This paper contributes to the body of knowledge by utilising a procedure of decision making method to select to an appropriate industrialized building system by examining key factors of user comfort attributes. Substantial reliance of results on long and deep interviews with building experts has commingled industrial part to this academic research that could promote validity of the driven results. In order to generalize the result of this study, future research can recruit more participants from different countries.

\section{REFERENCES}

Blismas, N., C. Pasquire and A. Gibb (2006). "Benefit evaluation for off-site production in construction." Construction Management and Economics 24(2): 121-130.

Brans, J.-P., P. Vincke and B. Mareschal (1986). "How to select and how to rank projects: The PROMETHEE method." European Journal of Operational Research 24(2): 228-238.

Gupta, U. G. and R. E. Clarke (1996). "Theory and applications of the Delphi technique: A bibliography (1975-1994)." Technological forecasting and social change 53(2): 185-211.

Kalkan, E. and S. B. Yüksel (2008). "Pros and cons of multistory RC tunnel-form (box-type) buildings." The Structural Design of Tall and Special Buildings 17(3): 601-617.

Karamlou, A. and M. Z. Kabir (2012). "Experimental study of L-shaped slender R-ICF shear walls under cyclic lateral loading." Engineering Structures 36: 134-146. 
Misagh, I. (2014). Psychological issues in building construction. B. Shahbazi. Tehran, Sharif university of technology, school of civil engineering, sharif civil magazine.

Pan, W., A. G. Gibb and A. R. Dainty (2007). "Perspectives of UK housebuilders on the use of offsite modern methods of construction." Construction Management and Economics 25(2): 183-194.

Paton-Cole, V. P., E. F. Gad, C. Clifton, N. T. Lam, C. Davies and S. Hicks (2012). "Out-ofplane performance of a brick veneer steel-framed house subjected to seismic loads." Construction and Building Materials 28(1): 779-790. 